\title{
Vulvovaginal Candidosis (excluding chronic mucocutaneous candidosis). Guideline of the German Society of Gynecology and Obstetrics (AWMF Registry No. 015/072, S2k Level, December 2013)
}

\author{
Die Vulvovaginalkandidose (außer chronisch mukokutaner Kandidose). Leitlinie der Deutschen Gesellschaft \\ für Gynäkologie und Geburtshilfe (AWMF-Registernummer 015/072, S2k-Level, Dezember 2013)
}

Authors

Affiliations
W. Mendling ${ }^{1}$, K. Friese ${ }^{2}$, I. Mylonas ${ }^{2}$, E.-R. Weissenbacher ${ }^{3}$, J. Brasch ${ }^{4}$, M. Schaller ${ }^{5}$, P. Mayser ${ }^{6}$, I. Effendy ${ }^{7}$, G. Ginter-Hanselmayer ${ }^{8}$, H. Hof $^{9}$, O. Cornely ${ }^{10}$, M. Ruhnke ${ }^{11}$

The affiliations are listed at the end of the article.
Deutschsprachige Zusatzinformationen online abrufbar unter: www.thieme-connect.de/ ejournals/toc/gebfra

\author{
Bibliography \\ DOI http://dx.doi.org/ \\ 10.1055/s-0035-1545741 \\ Geburtsh Frauenheilk 2015; 75 : \\ 342-354 ๑ Georg Thieme \\ Verlag KG Stuttgart · New York . \\ ISSN 0016-5751 \\ Correspondence \\ Prof. Dr. med. \\ Werner Mendling \\ Deutsches Zentrum für \\ Infektionen in Gynäkologie \\ und Geburtshilfe \\ St. Anna-Klinik \\ Vogelsangstraße 106 \\ 42109 Wuppertal \\ w.mendling@t-online.de
}

\section{Guideline Information}

Editor

Lead professional organization

German Society for Gynaecology and Obstetrics

(Deutsche Gesellschaft für Gynäkologie

und Geburtshilfe [DGGG] e. V.

Head Office of DGGG and Professional Societies

Hausvogteiplatz 12

10117 Berlin

Tel.: + 49 (0) 30-514883340

Fax: +49 (0) 30-514883344

info@dggg.de

http://www.dggg.de/

\section{President of the DGGG}

Prof. Dr. med. Diethelm Wallwiener

Universitätsfrauenklinik Tübingen

Calwerstraße 7

72076 Tübingen

\section{DGGG Guidelines Representative}

Prof. Dr. Matthias W. Beckmann

Universitätsklinikum Erlangen-Nürnberg

Frauenklinik

Universitätsstraße 21-23

91054 Erlangen

\section{DGGG Guidelines Secretariat}

Dr. Paul Gaß, Tobias Brodkorb, Marion Gebhardt Universitätsklinikum Erlangen-Nürnberg

Frauenklinik

Universitätsstraße 21-23

91054 Erlangen

Tel.: + 49 (0) 9131-85/44063

or +49 (0) $9131-85 / 33507$

Fax: +49 (0) 9131-85/33951

fk-dggg-leitlinien@uk-erlangen.de

http://www.dggg.de/leitlinienstellungnahmen

\section{Citation format}

Vulvovaginal Candidosis (excluding chronic mucocutaneous candidosis). Guideline of the German Society of Gynecology and Obstetrics (AWMF Registry No. 015/072, S2k Level, December 2013). Geburtsh Frauenheilk 2015; 75: 342-354

\section{Guideline documents}

The editorially complete, long version of these guidelines as well as a summary of the conflicts of interest of all the authors can be found on the homepage of AWMF: http://www.awmf.org/leitlinien/detail/ll/015-072.html

\section{Authors \\ See $\bullet$ Table 1.}

\section{Summary}

The estrogenized vagina is colonized by Candida species in at least $20 \%$ of women; in late pregnancy and in immunosuppressed patients this increases to at least 30\%. In most cases Candida albicans is involved.

Host factors, particularly local defense mechanisms, gene polymorphisms, allergies, serum glucose levels, antibiotics, psycho-social stress and estrogens influence the risk of candidal vulvovaginitis. Non-albicans species, particularly Candida glabrata, and in rare cases also Saccharomyces cerevisiae, cause less than $10 \%$ of all cases of vulvovaginitis with some regional variation; these are generally associated with milder signs and symptoms than normally seen with a Candida albicans-associated vaginitis.

Typical symptoms include premenstrual itching, burning, redness and odorless discharge. Although itching and redness of the introitus and vagina are typical symptoms, only $35-40 \%$ of women reporting genital itching in fact suffer from vulvovaginal candidosis. 
Table 1 Authors.

\begin{tabular}{|c|c|}
\hline \multirow{2}{*}{\multicolumn{2}{|c|}{ GG Consortium (AG)/AWMF/non-AWMF Professional Societies/Organisation/Associ }} \\
\hline & \\
\hline \multirow[t]{5}{*}{ Prof. Dr. Werner Mendling } & (responsible, leading) \\
\hline & German Society for Gynecology and Obstetrics (Deutsche Gesellschaft für Gynäkologie und Geburtshilfe DGGG) \\
\hline & Working Group on Infections and Immunology in Gynecology and Obstetrics \\
\hline & (Arbeitsgemeinschaft für Infektionen und Infektionsimmunologie in der Gynäkologie und Geburtshilfe AGII) \\
\hline & German Mycological Society (Deutschsprachige Mykologische Gesellschaft DMyKG) \\
\hline \multirow[t]{3}{*}{ Prof. Dr. Klaus Friese } & German Society for Gynecology and Obstetrics (Deutsche Gesellschaft für Gynäkologie und Geburtshilfe DGGG) \\
\hline & Working Group on Infections and Immunology in Gynecology and Obstetrics \\
\hline & (Arbeitsgemeinschaft für Infektionen und Infektionsimmunologie in der Gynäkologie und Geburtshilfe AGII) \\
\hline \multirow[t]{2}{*}{ Prof. Dr. Ioannis Mylonas } & German Society for Gynecology and Obstetrics (Deutsche Gesellschaft für Gynäkologie und Geburtshilfe DGGG) \\
\hline & $\begin{array}{l}\text { Working Group on Infections and Immunology in Gynecology and Obstetrics } \\
\text { (Arbeitsgemeinschaft für Infektionen und Infektionsimmunologie in der Gynäkologie und Geburtshilfe AGII) }\end{array}$ \\
\hline \multirow[t]{3}{*}{ Prof. Dr. Ernst-Rainer Weissenbacher } & German Society for Gynecology and Obstetrics (Deutsche Gesellschaft für Gynäkologie und Geburtshilfe DGGG) \\
\hline & Working Group on Infections and Immunology in Gynecology and Obstetrics \\
\hline & (Arbeitsgemeinschaft für Infektionen und Infektionsimmunologie in der Gynäkologie und Geburtshilfe AGII) \\
\hline \multicolumn{2}{|r|}{ (2) } \\
\hline \multirow[t]{2}{*}{ Prof. Dr. Jochen Brasch } & German Dermatological Society (Deutsche Dermatologische Gesellschaft DDG) \\
\hline & $\begin{array}{l}\text { German Mycological Society (Deutschsprachige Mykologische Gesellschaft DMyKG) } \\
\text { (leading) }\end{array}$ \\
\hline \multirow[t]{2}{*}{ Prof. Dr. Martin Schaller } & German Dermatological Society (Deutsche Dermatologische Gesellschaft DDG) \\
\hline & German Mycological Society (Deutschsprachige Mykologische Gesellschaft DMyKG) \\
\hline \multirow[t]{2}{*}{ Prof. Dr. Peter Mayser } & German Dermatological Society (Deutsche Dermatologische Gesellschaft DDG) \\
\hline & German Mycological Society (Deutschsprachige Mykologische Gesellschaft DMyKG) \\
\hline \multirow[t]{2}{*}{ Prof. Dr. Isaak Effendy } & German Dermatological Society (Deutsche Dermatologische Gesellschaft DDG) \\
\hline & German Mycological Society (Deutschsprachige Mykologische Gesellschaft DMyKG) \\
\hline \multirow[t]{2}{*}{ Prof. Dr. Gabriele Ginter-Hanselmayer } & German Dermatological Society (Deutsche Dermatologische Gesellschaft DDG) \\
\hline & German Mycological Society (Deutschsprachige Mykologische Gesellschaft DMyKG) \\
\hline \multicolumn{2}{|l|}{ Mikrobiologists } \\
\hline Prof. Dr. Herbert Hof & German Mycological Society (Deutschsprachige Mykologische Gesellschaft DMyKG) \\
\hline \multicolumn{2}{|l|}{ Hemato-Oncologists } \\
\hline Prof. Dr. Oliver Cornely & German Mycological Society (Deutschsprachige Mykologische Gesellschaft DMyKG) \\
\hline Prof. Dr. Markus Ruhnke & German Mycological Society (Deutschsprachige Mykologische Gesellschaft DMyKG) \\
\hline
\end{tabular}

Medical history, clinical examination and microscopic examination of vaginal content using $400 \times$ optical magnification, or preferably phase contrast microscopy, are essential for diagnosis. In clinically and microscopically unclear cases and in chronically recurring cases, a fungal culture for pathogen determination should be performed. In the event of non-Candida albicans species the minimum inhibitory concentration (MIC) should also be determined.

Chronic mucocutaneous candidosis, a rarer disorder which can occur in both sexes, has other causes and requires different diagnostic and treatment measures.

Treatment with all antimycotic agents on the market (polyenes such as nystatin; imidazoles, such as clotrimazole; and many others including ciclopirox olamine) is easy to administer in acute cases and is successful in more than $80 \%$ of cases. All vaginal preparations of polyenes, imidazoles and ciclopirox olamine and oral triazoles (fluconazole, itraconazole) are equally effective ( Table 4), however oral triazoles should not be administered during pregnancy according to the manufacturers. Candida glabrata is not sufficiently sensitive to the usual dosages of antimycotic agents approved for gynecological use. In other countries vaginal suppositories of boric acid (600 mg, 1-2 times daily for 14 days) or flucytosine are recommended. Boric acid treatment is not allowed in Germany and flucytosine is not available. $800 \mathrm{mg}$ oral fluconazole per day for 2-3 weeks is therefore recommended in Germany. Due to the clinical persistence of Candida glabrata despite treatment with high-dose fluconazole, oral posaconazole and, more recently, echinocandins such as mica- fungin are under discussion; echinocandins are very expensive, are not approved for this indication and are not supported by clinical evidence of their efficacy. In cases of vulvovaginal candidosis, resistance to Candida albicans does not play a significant role in the use of polyenes or azoles.

Candida krusei is resistant to the triazoles fluconazole and itraconazole. For this reason, local imidazole, ciclopirox olamine or nystatin should be used. There are no studies to support this recommendation, however. Side effects, toxicity, embryotoxicity and allergies are not clinically significant. Vaginal treatment with clotrimazole in the first trimester of a pregnancy reduces the rate of premature births.

Although it is not necessary to treat a vaginal colonization of Candida in healthy women, vaginal administration of antimycotics is often recommended in the third trimester of pregnancy in Germany in order to reduce the rate of oral thrush and diaper dermatitis in healthy full-term newborns.

Chronic recurrent vulvovaginal candidosis (CRVVC) continues to be treated in intervals using suppressive therapy as long as immunological treatments are not available. The relapse rate associated with weekly or monthly oral fluconazole treatment over 6 months is approximately $50 \%$ after the conclusion of suppressive therapy according to current studies. Good results have been achieved with a fluconazole regimen using an initial $200 \mathrm{mg}$ fluconazole per day on three days in the first week and a dosage-reduced maintenance therapy with $200 \mathrm{mg}$ once a month for one year when the patient is free of symptoms and fungal infection ( Fig. 2). Future studies should include Candida autovaccination, antibodies to 
Candida virulence factors and other immunological experiments. Probiotics with appropriate lactobacillus strains should also be examined in future studies on the basis of encouraging initial results. Because of the high rate of false indications, OTC treatment (self-treatment by the patient) should be discouraged.

\section{Methods}

A Medline/PubMed search was conducted using the keyword "vulvovaginal candidosis" (as of 2/2010) which produced 2886 articles; a search using the keywords "vulvovaginal candidosis therapy studies" produced 237 reviews. All were browsed according to title and abstract, however a few randomized and prospective controlled studies were left over $[31,43,70,108,134$, 145]. There were only 3 metanalyses or Cochrane analyses [ 105 , $150,159]$ and two guidelines $[13,82]$. For this revision another search was conducted using the same methods to identify articles from the last 5 years (as of 10.11.2013); this revealed 357 hits, with 44 review articles and 32 clinical studies. Systematic evaluation of the literature and extraction into evidence tables were not performed due to this guideline's classification as consensus-based. The literature was nonetheless critically evaluated by the participating experts.

Regarding consensus, patient participation, assessment and management of potential conflicts of interest, participation of professional societies and validity, see the Guideline Report in the annex.

\section{Use of the Guidelines}

\section{Introduction}

Vulvovaginal candidosis is an infection of the estrogenized vagina and vestibulum which can also extend to the outer sides of the labia minora, the labia majora, the intercrural region and the perineal region. Candidosis of the cervix or endometrium is unknown. Connatal fetal candidosis and candidal amnionitis are rare.

The terms "vulvovaginal candidosis" and "Candida albicans vulvovaginitis" are preferred [99]. The suffix “-iasis" should be reserved for parasitic infections such as trichomoniasis [69], but is unfortunately widely used in the Anglo-American literature.

\section{2}

\section{Summary of Recommendations}

2.1 The diagnosis of vulvovaginal candidosis is always made based on the combined basis of medical history, clinical signs and symptoms, as well as evidence of yeasts, which is normally found through microscopic examination of a native preparation of vaginal fluid ( $400 \times$ optical magnification, or preferably phase contrast microscopy). In uncertain, recurring and complex cases, a yeast culture is necessary to determine the species. Serological determination of antibody titers is not recommended.

2.2 Topical treatment of acute vulvovaginal candidosis can be performed for a period of one day to one week using polyene (nystatin), imidazoles or ciclopirox olamine using a number of different preparations such as vaginal tablets, suppositories or creams; oral triazoles (one-day treatment) and antimycotic creams for the vulva may also be used. All of the different treatment regimens produced similarly good clinical and mycological results. Data is limited regarding treatment with antiseptics (hexetidine, octenidine, dequalinium chloride), although there are indications of their efficacy. These substances also affect the physiological flora of the vagina.

It is not necessary to treat an asymptomatic colonization, provided that immune suppression, concomitant disease or chronic recurring vulvovaginal candidosis are not present. See 9.2 for treatment of vaginal colonization during pregnancy.

2.3 Topical treatment of chronically recurring Candida albicans vulvovaginitis consists of supressive antimycotic treatment with an oral triazole in intervals over a period of several months due to the lack of options for immunological treatment of causal factors. The best results have been achieved using the fluconazole treatment regimen developed by Donders et al. [31] ( 0 Fig. 2).

2.4 The typical oral and vaginal treatments for Candida albicans are less, or barely, effective for Candida glabrata vaginitis. For this reason, vaginal suppositories of $600 \mathrm{mg}$ boric acid once a day for 14 days are recommended in other countries. Several authors also recommend amphotericin B suppositories, vaginal application of $17 \%$ flucytosine or $800 \mathrm{mg}$ oral fluconazole per day for 2-3 weeks (see also 9.7). In Germany, oral posaconazole is recommended in combination with local nystatin and/or ciclopirox olamine treatment, as well as micafungin [143].

Candida krusei is practically resistant to fluconazole and itraconazole (also imidazole in vitro, but not in vivo) and should therefore be treated with local imidazoles, for example clotrimazole or ciclopirox olamine (or boric acid in the USA).

2.5 In Germany, antimycotic treatment of asymptomatic vaginal Candida colonization is recommended during the final 6 weeks of pregnancy in order to prevent vertical transmission to healthy, full-term newborns during vaginal birth. This can significantly reduce neonatal Candida infections attributable to maternal colonization, which normally appear in the 2nd to 4th weeks of life in more than $10 \%$ of healthy, full-term newborns (see also 9.2).

\section{$3 \quad$ Microbiology}

Candida albicans forms in vitro blastospores, germ tubes, pseudomycelia, true mycelia and also chlamydospores on special culture media. Candida glabrata appears almost exclusively as a blastospore. The formation of pseudohyphae (except Candida glabrata and several other Candida species, which only appear as blastospores) indicates an infection $[83,133]$.

Candida species and strains differ in their pathogenicity (in vitro), so that the development of a candidosis depends on the Candida species and the relative strength or weakness of the host's defense mechanisms [8].

85-95\% of the Candida species colonizing the vagina in premenopausal and pregnant, asymptomatic, healthy women and in women with acute vaginal candidosis are Candida albicans. Close relatives are Candida stellatoidea, which seems to be rare in vulvovaginal candidoses ( $\bullet$ Fig. 1 and Table 2 ), and Candida africana ( Table 3). Both were only identified by special diagnostic procedures $[117,128]$. Exact epidemiologic data are missing. Non-Candida albicans species, particularly Candida glabrata, are more likely to be identified in postmenopausal, diabetic and immune-suppressed women $[23,52,53,67,81,98,100]$. There are significant regional differences in the distribution of Candida species ( Fig. 1 and Table 2 as an example for Berlin) but no evi- 


\begin{tabular}{|c|c|c|c|c|c|c|}
\hline Species & $\begin{array}{l}\text { HIV-negative } \\
n=383\end{array}$ & $100 \%$ & & $\begin{array}{c}\text { HIV-positive } \\
n=66\end{array}$ & $100 \%$ & $\begin{array}{l}\text { Fig. } 1 \text { Candida colonization of the vagina } \\
\text { in healthy women [81]. }\end{array}$ \\
\hline \multicolumn{7}{|l|}{ Candida } \\
\hline Positive & 88 & 22.9 & $p=0.02$ & 24 & 36.4 & \\
\hline All & 88 & 100 & & 24 & 100 & \\
\hline C. albicans & 77 & 87.5 & & 14 & 58.3 & \\
\hline C. glabrata & 6 & 6.8 & \multirow{3}{*}{$p=0.001$} & 8 & 33.3 & \\
\hline C. krusei & 2 & 2.3 & & 0 & 0 & \\
\hline C. dubliniensis & 1 & 1.1 & & 0 & 0 & \\
\hline C. parapsilosis & 1 & 1.1 & & 1 & 4.2 & \\
\hline C. famata & 1 & 1.1 & & 0 & 0 & \\
\hline C. magnoliae & & & & 1 & 4.2 & \\
\hline
\end{tabular}

Table 2 Distribution of vaginal Candida species in HIV-negative colonized women [81].

\begin{tabular}{|c|c|c|c|c|c|c|c|c|}
\hline Patients & \multicolumn{2}{|c|}{ premenopausal } & \multicolumn{2}{|c|}{ postmenopausal } & \multicolumn{2}{|c|}{ pregnant } & \multicolumn{2}{|c|}{ not pregnant } \\
\hline All & \multicolumn{2}{|c|}{$\mathrm{n}=338$} & \multicolumn{2}{|c|}{$n=45$} & \multicolumn{2}{|c|}{$n=192$} & \multicolumn{2}{|c|}{$n=146$} \\
\hline \multirow[t]{3}{*}{ With positive culture } & \multicolumn{2}{|c|}{$\mathrm{n}=92(23.3 \%)$} & \multicolumn{2}{|c|}{$\mathrm{n}=6(13.3 \%)$} & \multicolumn{2}{|c|}{$n=52(27.1 \%)$} & \multicolumn{2}{|c|}{$\mathrm{n}=30(20.5 \%)$} \\
\hline & \multicolumn{4}{|c|}{$p=0.003$} & \multicolumn{4}{|c|}{$p=0.02$} \\
\hline & $\mathrm{n}$ & $\%$ & $\mathrm{n}$ & $\%$ & $\mathrm{n}$ & $\%$ & $\mathrm{n}$ & $\%$ \\
\hline C. albicans & 75 & 91.5 & 2 & 33.3 & 48 & 92.3 & 27 & 90.0 \\
\hline C. glabrata & 4 & 4.9 & 2 & 33.3 & 2 & 3.8 & 2 & 6.7 \\
\hline C. krusei & 1 & 1.2 & 1 & 16.7 & 1 & 1.9 & 0 & - \\
\hline C. dubliniensis & 1 & 1.2 & 0 & - & 1 & 1.9 & 0 & - \\
\hline C. famata & 0 & - & 1 & 16.7 & 0 & - & 0 & - \\
\hline C. parapsilosis & 1 & 1.2 & 0 & - & 0 & - & 1 & 3.3 \\
\hline
\end{tabular}

Table 3 Distribution of Candida species in 472 cases of acute vaginal candidosis in Poland and Germany [80].

\begin{tabular}{|c|c|c|}
\hline & $\mathbf{n}$ & $\%$ \\
\hline Acute Candida vulvovaginitis & 472 & 100 \\
\hline C. albicans & 450 & 95.3 \\
\hline C. glabrata & 10 & 2.1 \\
\hline C. krusei & 4 & 0.9 \\
\hline Other (C. tropicalis, C. kefyr, C. africana, S. cerevisiae) & 11 & 2.3 \\
\hline
\end{tabular}

dence for the increased occurrence of non-Candida albicans species in vaginal colonization. In a retrospective, four-year, PCRbased study of 93775 cervical-vaginal smears taken for the clarification of vulvovaginal candidosis, C. albicans was found in $89 \%$, C. glabrata in $7.9 \%$ and other Candida species in less than $2 \%$ of samples [147]; similar incidences were found in German [80,81] ( Table 3) and British studies [55].

Candida krusei, Candida guilliermondii, Candida tropicalis, Candida parapsilosis and other species can cause vulvovaginitis with typical symptoms in individual cases $[81,97,129,133,138]$.

Saccharomyces cerevisiae very rarely causes vaginal complaints $[83,131]$ but has been identified asymptomatically in 1 to $2 \%$ of vaginal cultures $[81,100]$ ( Table 3 ).

Different genotypes of Candida albicans strains have been identified in asymptomatic women and in those with acute Candida vaginitis [68]. Identical Candida albicans strains could be identified in the oro-intestinal tract and in the vagina of the same woman, as well as the sperm of her asymptomatic partner using PCR [79].

\section{Virulence Factors of Candida albicans}

The first step between colonization and infection is the attachment of the Candida cell to the vaginal wall with the help of mannoproteins $[38,135,142]$.

The capacity to form pseudohyphae and the secretion of hydrolytic proteins such as secretory aspartate proteinases (Sap 1-10) are probably the most significant virulence factors $[7,92,120]$. These correlate with pathogenicity $[16,51]$.

Siderophores enable the use of the host's iron [50,60]. Additional host factors are a strong $\mathrm{pH}$ tolerance of 2 to 11 [75] and enzymes which enable Candida albicans to survive in macrophages [66].

Bacteria and fungi can form biofilms in which they are highly organized in a matrix substance either alone or symbiotically, and protected. Auler et al. [4] and Chassot et al. [21] describe a biofilm phenomenon involving $C$. albicans on intrauterine pessaries. In systematic examinations of women with vulvovaginal candidosis in Berlin and China using a clear definition of biofilm, non-Candida biofilms were found in numerous vaginal tissue samples; the well-known phenomenon that Candida pseudohyphae penetrate vaginal tissue 8 to 10 cell layers deep [126] and that numerous other bacteria in abnormal vaginal flora enable penetration was recently demonstrated in vulvovaginal candidosis using fluorescence in situ hybridization (FISH) [139]. 
The step between colonization and vaginitis is not yet fully understood and highlights the importance of host factors [41]. It can be said attachment to the vaginal epithelium occurs after colonization, and then, with the help of Candida virulence factors, particularly secretory aspartate proteases, invasion, infection and inflammation result.

\section{$5 \quad$ Genital Colonization}

On account of the estrogenization of the vagina [29] and the estrogen receptors of Candida albicans $[107,140]$, pre-menarchal girls and post-menopausal women are less frequently vaginally colonized and generally do not suffer from Candida vaginitis. It has also been confirmed in animal tests that vaginal candidosis can only occur in sterilized animals after the administration of estrogen. Healthy, pre-menopausal women who are not pregnant are vaginally colonized in approximately 20 to $30 \%$ of cases, at least $30 \%$ of pregnant women are colonized in the third trimester and at least 30\% of immune-deficient women are found to be colonized to the extent that cultures are used for detection $[81,98]$ ( Fig. 1 and Table 2). With PCR, the detection of a vaginal Candida colonization is at least $10 \%$ higher [152]. Vaginal colonization can vary individually from time to time. In a longitudinal cohort study with 1248 healthy, asymptomatic young women, $70 \%$ were colonized at least once over the course of one year, although only $4 \%$ were colonized at all visits which took place every three months. Recent sexual intercourse, the injection of medroxyprogesterone acetate (an ovulation inhibitor) and simultaneous colonization with lactobacillus and B streptococcus were identified as risk factors [6].

The partner's sperm can be colonized with the identical Candida strain as in the vagina [79], even when the partner is symptomfree. Candida balanitis should be treated, although temporary redness of the glans after intercourse with a Candida-colonized woman can also represent an allergic response to Candida antigens. It is not clear whether the colonization of the partner's genital tract or the oro-intestinal tract of both partners can play a role in chronic recurring Candida vaginitis [133].

There is no evidence of an increase in the incidence of either acute or chronic recurring vaginal candidosis in gynecology.

\section{6}

\section{Predisposing Host Factors}

Patients with diabetes mellitus suffer from vaginal candidosis more frequently and treatment is likely to fail when serum glucose levels are not normalized [12].

Lower glucose tolerance was also found in approximately $25 \%$ more women with CRVVC than in healthy controls [32]. Obesity, in conjunction with intertrigo caused by rubbing and sweating, can contribute to candidosis in the genital area.

Although Candida glabrata is less virulent, women with Type II diabetes mellitus are more frequently colonized than healthy women [67, 109].

Vaginal Candida colonization is probably not increased by modern oral contraceptives with low estrogen levels [28], which do not significantly influence carbohydrate metabolism [48]. This also applies to the frequency of vaginal candidosis [44]. There are some contradictory observations, however [19,122]. In a systematic review of the literature others have observed an increase in vulvovaginal candidosis when oral contraceptives are used, although this depends on the estrogen dosage [153].

Women with high estrogen levels, and particularly during pregnancy, more regularly experience vaginal Candida colonization. Women who are already vaginally colonized by Candida species have an up to $33 \%$ higher risk of developing a vaginal candidosis after treatment with antibiotics [34,102,104,159].

Although vaginal candidosis often occurs in women with normal lactobacillus flora, lower numbers of lactobacilli have been found in women with vaginal candidosis [3]. It is assumed meanwhile that special strains of lactobacilli (for example Lactobacillus rhamnosus) can play a protective role against vaginal candidosis $[71,72]$.

Sobel [133] emphasizes the likely underestimated role of sexual activity in the recurrence of vaginal candidosis, as re-infections are frequently observed after sexual intercourse, particularly oro-genital contact $[34,111,122]$.

Finally, genetic factors are also responsible for recurrences; gene polymorphisms of mannose-binding lectin $[5,30]$ and a non-secretor pheneotype of the ABO-Lewis blood group have been identified as risk factors [20].

Four female members of a Dutch family were affected either by recurring vulvovaginal candidosis or onychomycosis and displayed a specific mutation (loss of the last 9 amino acids in the carbohydrate recognition domain). The modified form of the lectin Dectin-1 caused by this mutation led to insufficient production of cytokines (interleukin-17, tumor necrosis factor, interleukin-6) after stimulation with beta-glucan or Candida albicans. In contrast, phagocytosis and elimination of fungi was unaffected in these patients, which explains why a lack of Dectin-1 is not associated with fungal infections. Interestingly, symptoms appeared in the homozygotic daughters between 10-12 years of age, while the age of manifestation in the heterozygotic mother and father was between 40 and 55 years; this suggests both hormonal and gene-dosage effects [40]. The documented mutation is notably common in parts of Africa and Europe (3-7\%).

Meanwhile deeper insights have been gained in the complex field of innate and acquired immunity. Of interest are the known factors of innate and acquired humoral immunity and the factors which should neutralize Candida in order to prevent the steps between asymptomatic colonization, attachment and infection. Vaginal microbiota also play a not yet sufficiently understood role. Th-1-induced dendritic $\mathrm{T}$ cells/Langerhans cells are supported by interleukin 12 . Oral and vaginal epithelial cells are capable of differentiating the Candida polymorphism (colonizing blastospores or infectious pseudohyphae). They then produce proinflammatory cytokines which activate neutrophils. These are not protective in the vagina, however, and cause inflammation here instead. Recently, the importance of antibodies to parts of Candida was (again) recognized. It was found the antibodyproducing $\mathrm{B}$ cells have protective effects in vaginal candidosis $[18,58,62,116,146]$.

Women with an atopic diathesis and type 1 allergies develop vaginal candidosis significantly more often than others [93]. The clinical symptoms of vaginal candidosis, such as redness and itching, are seen as an expression of allergic phenomena, particularly in recurring cases $[133,156]$.

Women with a history of recurring Candida vaginitis express heat shock proteins during symptom-free intervals, which can provoke similar immunological defense reactions in the same way as Candida cells $[49,110]$. 
Psychosocial stress can also trigger CRVVC, likely due to immune suppression $[35,87]$. Vice versa, CRVVC has a considerable negative influence on the patient's professional and private life [85]. Because infection requires both colonization and disposition candidosis is the infection of the infected - immune-suppressed individuals are particularly likely to develop candidosis. $75 \%$ of otherwise healthy women develop vulvovaginal candidosis at least once in their lives and many experience more than 4 episodes per year (chronic recurring vulvovaginal candidosis/ CRVVC) $[23,133]$. In an internet questionnaire with 6000 women in 5 European countries and the USA, 30-50\% of women in each country reported having vulvovaginal candidosis at least once, and approximately 9\% suffered from CRVVC for several years [45]. Nonetheless, no correlation was found between the frequency of antibiotic prescriptions and chronic recurring vulvovaginal candidosis.

\section{Clinical Symptoms}

Due to the influence of estrogen, pre-menopausal women normally suffer primarily from vaginal candidosis, which can extend to the vulva, while post-menopausal women typically suffer from vulvar and/or intercrural candidosis. Clinical symptoms typically appear prior to menstruation: the cell proliferation induced by estrogens and the cytolysis induced by progesterone releases glycogen, which can be metabolized by lactobacilli, increase glucose levels in the vagina [34].

In approximately $90 \%$ of patients, itching is the most important, but not the most reliable, symptom, as only $35-40 \%$ of the women suffering from itching are found to have vaginal candidosis [2, $81,152]$. Discharge can range widely from fluid (often at the start of an acute vaginal candidosis) to clumpy, or in CRVVC can be entirely absent [137]. Vulvovaginal candidoses can be divided into simple and complex cases from a clinical and therapeutic standpoint [133]. The pseudohyphae used for differentiation are not always found microscopically in all cases of the so-called simple candidosis.

Most patients complain of vaginal redness, soreness, burning, dyspareunia and dysuria. These symptoms alone are not sufficient for the clinician to reliably determine the causes of an episode of vaginitis. On the other hand, itching and redness are very rarely absent in vaginal candidosis [2]. The discharge does not have an unpleasant odor in contrast to bacterial vaginosis. The inner labia can be odematous, and burning fissures are seen particularly in CRVVC.

From a dermatological standpoint, vulvar candidosis can be divided into vesicular, eczematoid and follicular (hair follicle) forms (after [82]).

In severe cases, a thick layer of discharge can attach to the vaginal wall and lead to minor bleeding when removed.

Candida glabrata vaginitis is rare and generally occurs in the late pre-pausal and peri-pausal period $[42,55,76,132,138]$. Candida krusei vaginitis [129], Candida parapsilosis vaginitis [97] and the rare Saccharomyces cerevisiae vaginitis $[83,123,131]$ are generally similar to Candida glabrata vaginitis and are associated with only mild clinical symptoms.

Candida cervicitis is unknown.

In comparison to the general population and using established evaluation criteria, women with CRVVC are significantly impacted in their quality of life and health status in a manner comparable to asthma or chronic obstructive bronchitis and show sig- nificantly reduced productivity in their professional and daily lives [1].

\section{Diagnosis}

The diagnosis of vaginal candidosis is always made using a combination of medical history, clinical symptoms and the detection of yeasts. Clinical diagnosis can be difficult, as a vulvovaginal candidosis is not necessarily present even when Candida has been detected and itching of the introitus occurs. In a prospective study of the accuracy of clinical diagnosis of bacterial vaginosis, trichomoniasis and vulvovaginal candidosis in 535 soldiers with vulvovaginal complaints, the sensitivity and specificity of the diagnosis using classical diagnostic methods (medical history, vaginal examination, $\mathrm{pH}$-value, microscopy of native preparation) amounted to 83.8-84.8\% [70]; which corresponded with the earlier results of Müller et al. [90], whereas Candida could be identified in $20.9 \%$ using PCR in contrast to $14 \%$ of all women.

\subsection{Necessary diagnostics}

Medical history, gynecological examination and microscopic examination of discharge using a saline solution or $10 \%$ potassium hydroxide solution under $400 \times$ optical magnification, or preferably phase contrast microscopy, are essential for diagnosis [83,91]. $\mathrm{pH}$ measurement can also be performed if necessary. Blastospores or (pseudo-)hyphae can be found microscopically in approximately 50 to $80 \%$ of vaginal candidosis cases $[90,133]$, although they are only microscopically visible during colonization in approximately half of the cases. An increased number of leucocytes may be found in discharge, but this is not necessarily always the case. In the event that no blastospores or (pseudo-)hyphae can be found during microscopy or if the case is a CRVVC or is otherwise complicated, it is necessary to perform a culture in order to determine the species involved $[34,57,96]$.

Sabouraud glucose agar is the typical medium for performing diagnostic cultures. Other equally sensitive and reliable media are also available, including chrome agar for differentiation and $\mathrm{Mi}$ crostix-Candida.

It is possible that two or more different yeast species can be cultured in a case of vaginal candidosis, for example Candida albicans and Candida glabrata. The patient typically suffers from a Candida albicans vaginitis while the generally resistant Candida glabrata remains in situ after treatment. It is generally only present as a colonization and need not be treated again in the absence of symptoms.

In vitro sensitivity testing is not necessary and at most only if non-Candida albicans species are found and the infection chronically recurs.

\subsection{Unnecessary diagnostics}

Serological tests are not considered useful for the diagnosis of vulvovaginal candidosis because low levels of antibodies can be found in most people's blood. Antibodies are measurable in women both with and without vaginal candidosis (for example due to intestinal colonization). Superficial vaginal candidosis does not cause increased antibody levels. 
Treatment

There are a great number of options for conventional and alternative treatments [154]. Polyenes form complexes using the ergosterol of the yeast membranes and alter their permeability [124]. Azoles hinder the conversion of lanosterol to ergosterol in the yeast cell membranes [106]. Ciclopirox olamine hinders important iron-dependent enzymes through the formation of chelate [94].

\subsection{Colonization}

Even with high bacteria counts, asymptomatic vaginal colonization does not require treatment provided that the patient is immunocompetent and does not suffer from CRVVC.

\subsection{Colonization during pregnancy}

Almost all healthy full-term newborns who are colonized with Candida albicans during vaginal birth will develop oral thrush and/or diaper dermatitis at some point in the first year of life, peaking in the 2 nd to 4 th weeks $[10,11]$.

For this reason, prophylactic treatment of asymptomatic Candida colonization is recommended in Germany in the final weeks of pregnancy in order to prevent the colonization and subsequent infection of the newborn during vaginal birth. This significantly reduces the occurrence of oral thrush and diaper dermatitis from approximately 10 to $2 \%$ in the fourth week of life $[10,84,125]$.

In retrospective studies [24-26,54] and one prospective study [63] a significant reduction in premature births was found after vaginal treatment with clotrimazole in the first trimester of pregnancy. In an Australian study with a relatively small number of patients, only a non-significant reduction in premature births was observed after clotrimazole treatment in the first trimester [115]. It is under discussion whether non-Candida albicans species, inflammatory cytokines triggered by Candida in the vagina, or the antibacterial components of clotrimazole play the decisive role against gram-positive coccoids. More prospective studies are therefore needed.

Since the introduction of triazoles around 1990 no neonatal deformities have been observed in the first trimester [24,73]. According to a Danish study, the administration of fluconazole in typical gynecological dosages of $150-300 \mathrm{mg}$ /day is harmless throughout pregnancy. In a cohort of 7352 pregnancies, however, 7 incidences of Fallot tetralogy were found in association with the medically indicated cumulative administration of $150-6000 \mathrm{mg}$ of flucanozole in the first trimester; in the control group of 968236 pregnancies where no flucanozole was administered in the first trimester, a significantly lower incidence was reported [88].

\subsection{Treatment of acute vulvovaginal candidosis}

Acute vulvovaginal candidosis can be treated locally with polyenes (nystatin, amphotericin B), imidazoles (clotrimazole, miconazole nitrate, econazole nitrate, fenticonazole nitrate) [77, 133 ] or ciclopirox olamine [148] ( $\bullet$ Table 4).

Vaginal suppositories and creams are available with dosages and preparations for treatment periods ranging from 1 to 3 days and 6 or 7 days and are considered harmless for patients [114].

Oral treatment with the triazoles fluconazole and itraconazole are also possible.

The mycological and clinical success rates for the different approved treatment regimens are basically the same outside pregnancy and range from approximately $85 \%$ at one to two weeks and $75 \%$ at 4 to 6 weeks after treatment $[22,80,95,105,134]$.
Table 4 Antimycotic agents against vulvovaginal candidosis.

Polyenes (since ca. 1960):

- Nystatin: vaginal tablets or vaginal suppositories 100000 IE, 200000 IE for 6-day treatment, nystatin cream, nystatin ointment

- Amphotericin B (no longer available in Germany for vaginal treatment) Imidazoles (since ca. 1970):

- Clotrimazole, miconazole nitrate, econazole nitrate, fenticonazole nitrate and others in the form of vaginal tablets, vaginal suppositories, vaginal creams, skin creams (for the vulva and perineal areas). For example, $500 \mathrm{mg}$ clotrimazole vaginal tablets for 1-day treatment or $600 \mathrm{mg}$ fenticonazole nitrate in the form of a vaginal suppository; for 3-day treatment clotrimazole $200 \mathrm{mg}$ vaginal tablets or $2 \%$ vaginal cream; for 6 -day treatment $100 \mathrm{mg}$ clotrimazole vaginal tablets or $1 \%$ vaginal cream, etc. Oral imidazoles (since ca. 1980):

- Ketoconazole (no longer available in Germany)

Triazoles (since ca. 1990):

- Fluconazole $150 \mathrm{mg}$ hard capsules for 1-day treatment, fluconazole $50 \mathrm{mg}$, $100 \mathrm{mg}, 200 \mathrm{mg}$ capsules

- Itraconazole hard capsules 100 mg, $2 \times 200$ mg for 1-day treatment

Ciclopirox olamine (for gynacological treatment since ca. 1995):

- Vaginal cream $10 \mathrm{mg} / \mathrm{g}: 50 \mathrm{mg}$ daily for 6 days

Treatment success rates during pregnancy are significantly better with imidazoles than with polyenes [160].

In the event that the candidosis extends to the vulvar region outside the vaginal introitus or to the inguinal region, an antimycotic skin cream, for example clotrimazole, is recommended $2 \times$ daily for approximately one week. The combination of intravaginal treatment of acute vulvovaginal candidosis with additional cream for the vulva appears to produce better treatment results than intravaginal treatment alone. There are few studies available to support this, however $[86,108]$.

"Blind" treatment of the asymptomatic sexual partner is not beneficial for the patient $[9,14,133]$. No studies have been found which demonstrate a benefit for the patient from treating the asymptomatic sexual partner who is colonized on the penis or in the sperm.

Vaginal candidosis occurs much more frequently in HIV-positive women ( Fig. 1). This problem and the multiple issues involved in treatment are examined in the HIV guidelines regarding the treatment of opportunistic infections [141]. Sexual partners of HIV-positive women should be informed of the increased risk of infection if they display a predisposition to Candida balanitis.

\subsection{Side effects}

All vaginal and local antimycotics are well tolerated. Azoles and ciclopirox olamine can cause minor local burning in 1 to $10 \%$ of cases $[77,80]$. Allergic reactions are possible but rare.

Hydrophilic fluconazole and lipophilic itraconazole rarely cause side effects in normal dosages. Itraconazole causes significantly more side effects during systemic treatment than fluconazole (for example anaphylactic reactions, headaches, etc.).

\subsection{Resistence to Candida albicans?}

Although strains of vaginal Candida albicans have been found with higher minimal inhibitory concentrations against fluconazole [112], cases of azole resistance in vaginal candidosis are rare $[74,112]$. Clinical resistance does not correlate with minimal inhibitory concentrations and vice versa. For this reason resistance tests are generally not recommended [133], unless the case involves non-Candida albicans species. Sensitivity testing should 


\begin{tabular}{|c|c|}
\hline $\begin{array}{c}\text { Week 1: } \\
200 \text { mg fluconazole } \\
\text { day } 1,3 \text { and } 5\end{array}$ & $\begin{array}{l}\text { Prerequisite for next step: } \\
\text { Free of clinical symptoms, } \\
\text { mycology (microscopy, culture) }\end{array}$ \\
\hline $\begin{array}{c}\text { Weeks 2-8: } \\
200 \text { mg fluconazole } \\
1 \times / \text { week }\end{array}$ & $\begin{array}{l}\text { first step } \\
\text { Optimal responders: } \\
\text { Treatment ends after } 1 \text { year }\end{array}$ \\
\hline $\begin{array}{l}\text { Months 3-6: } \\
200 \text { mg fluconazole } \\
\text { every } 2 \text { weeks }\end{array}$ & $\begin{array}{l}\text { Sub-optimal: } \\
\text { Symptom-free, but recurrence } \\
\text { or symptom-free colonization }\end{array}$ \\
\hline $\begin{array}{l}\text { Months 7-12: } \\
200 \text { mg fluconazole } \\
\text { every } 4 \text { weeks }\end{array}$ & $\begin{array}{l}\text { Non-responders: } \\
\text { At least two recurrences }\end{array}$ \\
\hline
\end{tabular}

Fig. 2 Individualized, dose-reduced maintenance treatment with fluconazole in chronically recurring vulvovaginal candidosis (Donders et al. [31].

be performed in a laboratory experienced in mycology when a Candida albicans vulvovaginitis reappears after a longer period of chemoprophylaxis using fluconazole [127].

\subsection{Non-Candida albicans vaginitis}

Typical vaginal and oral treatments are generally unsuccessful against Candida glabrata vaginitis. Sobel et al. [136] therefore recommend vaginal suppositories containing $600 \mathrm{mg}$ boric acid for 14 days, while Philips [101] recommends amphotericin B. In treatment resistant cases, vaginal treatment for two weeks using $17 \%$ flucytosine is successful in $90 \%$ of cases [136]. Boric acid treatment is not permitted in Germany and vaginal flucytosine preparations are not available. It was therefore recommended until recently that $800 \mathrm{mg}$ fluconazole be administered orally for 2 to 3 weeks against Candida glabrata vaginitis (but not colonization!) $[65,82]$. Even with this treatment, failures have increasingly been seen. For this reason Tietz [143] recommended the oral administration of posaconazole together with local treatment with ciclopirox olamine and/or nystatin for 15 days on the basis of remission in 14 of 15 patients. He did begin to observe quickly emerging resistance as well as treatment failure with that regimen, however. He then described the successful treatment of 14 patients with $C$. glabrata infections of the vagina at several German universities and his own institute using micafungin, an echinochandin approved for the treatment of life-threatening mycoses, for example in hematooncology [144]. Such measures are only appropriate in exceptional cases involving significant illness as this is an "off-label", non-approved use.

Candida krusei vaginitis is resistent to fluconazole and flucytosin, however local clotrimazole, ciclopirox olamine $[83,144]$ and (for example, in the USA) boric acid [129] can be used. Nystatin treatment is also prone to failure. Due to the rareness of such cases, no results are available from clinical studies. There are also no studies available which compare antimycotics and antiseptics. Dequalinium chloride is effective in vitro [15], while octenidine and others have at least been tested as alternatives for acute vulvovaginal candidosis [46,47].

\subsection{Chronically recurring Candida albicans vulvovaginitis}

Because infection requires colonization and disposition and treatment of the underlying disposition (local weakness of the immune system) has not yet been attempted, local and oral maintenance treatments are recommended for the prevention of recurrences $[27,119,130,134]$. The results are comparable whether local clotrimazole $500 \mathrm{mg}$, oral ketoconazole $100 \mathrm{mg}$ or oral fluconazole $150 \mathrm{mg}$ are administered, however recurrence occurs in approximately half of all patients shortly after ending treatment $[130,134]$. In a placebo-controlled study with a randomized collective of 387 women who received $150 \mathrm{mg}$ fluconazole weekly for 6 months, the group of illness-free women after 12 months totaled $42.9 \%$ in the fluconazole group and $21.9 \%$ in the placebo group [134]. CRVVC is therefore comparable to a chronic, incurable disease [33].

The treatment and prophylaxis recommended by Donders et al. [31], which involves an initial dose of $3 \times 200 \mathrm{mg}$ fluconazole in the first week, followed by a dosage-reduced maintenance regimen ( Fig. 2), is beneficial as almost $90 \%$ of the patients were found to be illness-free after 6 months and $77 \%$ of the patients remained so at one year. The cumulative total dose amounted to $3800 \mathrm{mg}$ fluconazole in 6 months and $5000 \mathrm{mg}$ in one year according to Donders' treatment schedule. The administration of $150 \mathrm{mg}$ fluconazole per week amounts to $3600 \mathrm{mg}$ after 6 months, but $7200 \mathrm{mg}$ fluconazole at one year with the same treatment results.

Removal of intrauterine pessaries should be considered in women with recurring vulvovaginal candidosis because histology and culturing have shown that Candida albicans is significantly more likely to attach to plastic pessaries containing levonorgestrel in women with candidosis than in women without recurrences. After removal of the IUD and treatment with fluconazole, these women did not experience recurrences for a long period of time [161].

\section{0}

\section{Open Questions}

A number of questions remain open. How and why do immunological defense mechanisms in the vagina fail in a number of women and why do they allow recurring infections and inflammation after an acute episode of vaginal candidosis?

Antimycotic agents are clearly not the answer and only improve acute symptoms in such cases.

What role does a recurring Candida infection of the vulva or vagina play in the development of vestibulodynia? Many women with provoked secondary vestibulodynia report vulvovaginal candidosis before the appearance of vestibular pain. In animal testing a significant correlation could be found between vulvovaginal Candida infections and vestibulodynia as well as incrementation of an unusual number and density of nerves in the superficial epithelial layers accompanied by significant immunohistochemical changes [37].

\subsection{Immunological approaches to treatment}

A satisfactory immunological treatment for recurring vaginal candidosis has not yet been developed, although Rosedale and Brown [118] reported promising initial results of hyposensitization more than 30 years ago. In vitro studies using autologous membrane-bound Candida albicans antigens and $\mathrm{T}$ cells in a patient with chronic recurring Candida albicans vaginitis produced 
better immunological responses than commercial Candida antigens [64]. Rigg et al. [113] reported a Candida allergen treatment, while Moraes et al. [89] and Rusch and Schwiertz [121] reported results from a Candida autovaccination, which only used allergoid components as used in hyposensitization. There has yet to be a therapeutic breakthrough in this field, despite numerous experiments to better understand the immunopathogenicity of Candida vaginitis $[5,7,17,41,59,78,93,151,155,156,158]$. Intramuscular injection of non- $\mathrm{H}_{2} \mathrm{O}_{2}$-forming "aberrant" lactobacilli, which induce antibody formation and unspecific immune reactions and can be successfully used primarily against trichomoniasis and bacterial vaginosis, failed to reduce the number of recurrences of chronic recurring vulvovaginal candidosis although it did lead to significant improvement in individual scoring in regard to physical and psychological well-being [85].

Alongside a number of methods for inducing the production of antibodies against systemic candidosis, two vaccinations against oral and vulvovaginal candidosis have moved closer to clinical trial: one targets secretory aspartate protease 2 (Sap 2), the most important virulence factor of Candida albicans, while the other targets the agglutinin-like sequence 3 protein Als $3 p$, a cell wall antigen found on the surface of Candida. Both led to good antibody formation in animal tests as well as initial human studies, raising hopes for clinical efficacy in a manner similar to boostering $[18,146]$.

\subsection{The significance of lactobacilli}

The oral administration of probiotics containing specific lactobacillus strains $[36,56,61,103]$ have produced encouraging, yet controversial, results which require further investigation. Lactobacillus strains have been identified which have fungicidal and immune-stimulating effects in vitro [71] and have been found to significantly reduce vaginal colonization in vivo after treatment of vulvovaginal candidosis in comparison to placebo [72]. Over a period of six months, monthly administration of lactobacilli for six days in conjunction with itraconazole $2 \times 200 \mathrm{mg}$ for one day showed no improvement over itraconazole alone in the reduction of recurrence rates in chronic recurring vulvovaginal candidosis. Nonetheless, these treatment measures were found better than classical homeopathy with a high degree of significance [157].

\subsection{Over-the-counter treatment?}

Self-treatment ("over-the-counter" = OTC) of vulvovaginal candidosis using clotrimazole, and also fluconazole in several countries, is practiced meanwhile in more than $80 \%$ of cases. Although it was optimistically thought in the early 1990s that patients were almost always able to correctly diagnose vaginal candidosis themselves, this has meanwhile been proven to be incorrect (at least for now) $[6,57,149]$. Only one third of 95 women who purchased a vaginal antimycotic for self-treatment were found to have a Candida vaginitis [39]. It is therefore being recommended again that treatment should only take place after a correct medical diagnosis has been made.

\section{Future Research}

A number of gaps remain in our knowledge of Candida-host interactions and require further research. For example: How can Candida albicans virulence factors be counteracted? How can the attachment of Candida cells to the vaginal epithelium be reduced? How can the defense mechanisms of the vagina be strengthened (for example T lymphocyte stimulation, humoral factors, allergies)? Is it possible to vaccinate against Candida? Which new antimycotics are able to effectively treat Candida glabrata and Candida krusei intravaginally? How does Candida interact with vaginal flora, as it has been shown that abnormal bacterial flora of the vagina can penetrate the vaginal epithelium together with pseudohyphae, which is not normally the case in bacterial disorders of the vagina [139]. Why does clotrimazole treatment in early pregnancy reduce the number of premature births?

\section{Affiliations}

${ }^{1}$ Deutsches Zentrum für Infektionen in Gynäkologie und Geburtshilfe, Wuppertal

${ }^{2}$ Klinikum der Universität München, Klinik und Poliklinik für Frauenheilkunde und Geburtshilfe, München

3 Premium Medizin, München

${ }^{4}$ Universitätsklinikum Kiel, Klinik für Dermatologie, Kiel

${ }^{5}$ Universitäts-Hautklinik Tübingen, Tübingen

${ }^{6}$ Universitätsklinikum Giessen, Klinik für Dermatologie, Venerologie und Allergologie, Giessen

7 Klinikum Bielefeld, Hautklinik, Bielefeld

${ }^{8}$ Universitätsklinik für Dermatologie und Venerologie Graz, Graz, Österreich

${ }^{9}$ Labor Limbach, Heidelberg

${ }^{10}$ Uniklinik Köln, Klinik I für Innere Medizin, Köln

${ }^{11}$ Medizinische Klinik mit Schwerpunkt Onkologie und Hämatologie, Charité, Berlin

\section{References}

1 Aballéa S, Guelfucci F, Wagner J et al. Subjective health status and health-related quality of life among women with Recurrent Vulvovaginal Candidosis (RVVC) in Europe and the USA. Health Qual Life Outcomes 2013; 11: 169-173

2 Anderson MR, Klink $K$, Cohrssen A. Evaluation of vaginal complaints. JAMA 2004; 291: 1368-1379

3 Auger P, Joly J. Microbial flora associated with candida albicans vulvovaginitis. Am J Obstet Gynecol 1980; 55: 397-401

4 Auler ME, Morreiva D, Rodriguez FF, et al. Biofilm formation on intrauterine devices in patients with recurrent vulvovaginal candidiasis. Med Mycol 2010; 48: 211-216

5 Babula O, Lazdane G, Kroica J et al. Frequency of interlenkin-4 (IL-4)589 gene polymorphism and vaginal concentrations of IL-4, nitric oxide, and mannosebinding lectin in women with recurrent vulvovaginal candidiasis. Clin Infect Dis 2005; 40: 1258-1262

6 Beigi RH, Meyn LA, Moore DM et al. Vaginal yeast colonization in nonpregnant women: a longitudinal study. Obstet Gynecol 2004; 104: 926-930

7 de Bernardis F, Agatensi L, Ross IK et al. Evidence for a role for secretory asparatate proteinase of Candida albicans in vulvovaginal candidosis. J Infect Dis 1990; 161: 1276-1283

8 de Bernardis F, Boccanera M, Cassone A. The Role of Immunity against vaginal Candida Infection. In: Fidel PL, Huffnagle GB, eds. Fungal Immunity: from an Organ Perspective. Heidelberg, New York: Springer; 2005: 345-355

9 Bisschop MP, Merkus JM, Scheygrond $\mathrm{H}$ et al. Co-treatment of the male partner in vaginal candidosis: a double-blind randomized control study. Br J Obstet Gynaecol 1986; 93: 79-81

10 Blaschke-Hellmessen R. Subpartale Übertragung von Candida und ihre Konsequenzen. Vertical transmission of candida and its consequences. Mycoses 1998; 41 (Suppl. 2): 31-36

11 Blaschke-Hellmessen R. Epidemiologische Untersuchungen zum Vorkommen von Hefepilzen bei Kindern und deren Müttern. Mykosen 1968; 11: 611-616

12 Bohanna NJ. Treatment of vulvovaginal candidiasis in patients with diabetes. Diabetes Care 1998; 21: 451-456

13 Bond CM, Watson MC; Grampian Evidence Based Community Pharmacy Guidelines Group. The development of evidence-based guidelines for over-the-counter treatment of vulvovaginal candidiasis. Pharm World Sci 2003; 25: 177-181 
14 Buch A, Skytte Christensen E. Treatment of vaginal candidosis with natamycin and effect of treating the partner at the same time. Acta Obstet Gynecol Scand 1982; 61: 393-396

15 della Casa V, Noll H, Gonser S et al. Antimicrobial activity of dequalinium chloride against leading germs of vaginal infections. Arzneimittelforsch 2002; 52: 699-705

16 Cassone A, de Bernardis F, Mondell F et al. Evidence for a correlation between proteinase secretion and vulvovaginal candidosis. J Inf Dis 1987; 156: 777-782

17 Cassone A, de Bernardis F, Torososantucci A. An outline of the role of anti-candida antibodies within the context of passive immunization and protection from candidiasis. Curr Mol Med 2005; 5: 377-382

18 Cassone A, Casadevall A. Recent progress in vaccines against fungal diseases. Curr Opin Microbiol 2012; 4: 427-433

19 Cetin M, Ocak S, Gungoren A et al. Distribution of Candida species in women with vulvovaginal symptoms and their association with different ages and contraceptive methods. Scand J Infect Dis 2007; 39: 584588

20 Chaim W, Foxman B, Sobel JD. Association of recurrent vaginal candidiasis and secretory ABO and Lewis phenotype. J Infect Dis 1997; 176: 828-830

21 Chassot F, Negri MF, Swidsinski AF et al. Can intrauterine contraceptive devices be a Candida albicans reservoir? Contraception 2008; 77: 355359

22 Cohen $L$. Is more than one application of an antifungal necessary in the treatment of an acute vaginal candidosis? Am J Obstet Gynecol 1985; 152: 961-964

23 Corsello S, Spinillo A, Osnengo G et al. An epidemiological survey of vulvovaginal candidiasis in Italy. Eur J Obstet Gynecol Reprod Biol 2003; 110: $66-72$

24 Czeizel AE, Tóth M, Rockenbauer M. No teratogenic effect after clotrimazole therapy during pregnancy. Epidemiology 1999; 10: 437-440

25 Czeizel AE, Fladung B, Varga P. Preterm birth reduction after clotrimazole treatment during pregnancy. Eur J Obstet Gynecol Reprod Biol 2004; 116: 157-163

26 Czeizel AE, Puhó EH, Kazy Z. The use of data set of the Hungarian casecontrol surveillance of congenital abnormalities for evaluation of birth outcomes beyond birth defects. Centr Eur J Public Health 2007; 15 147-153

27 Davidson F, Mould RF. Recurrent vaginal candidosis in women and the effect of intermittent prophylactic treatment. BJ Vener Dis 1978; 54: $176-183$

28 Davidson F, Oates JK. The pill does not cause 'thrush'. Br J Obstet Gynaecol 1985; 92: 1265-1266

29 Dennerstein GJ, Ellis $\mathrm{DH}$. Oestrogen, glycogen and vaginal candidiasis. Aust N Z J Obstet Gynaecol 2001; 41: 326-328

30 Donders G, Babula O, Bellen $G$ et al. Mannose-binding lectin gene polymorphism and resistance to therapy in women with recurrent vulvovaginal candidiasis. BJOG 2008; 115: 1223-1231

31 Donders G, Bellen G, Byttebier G et al. Individualized decreasing dose maintenance fluconazole regimen for recurrent vulvovaginal candidiasis (ReCiDiF trial). Am J Obstet Gynecol 2008; 199: 613.e1-613.e9

32 Donders $G$, Prenen $H$, Verbeke $G$ et al. Impaired tolerance for glucose in women with recurrent vaginal candidiasis. Am J Obstet Gynecol 2002; 187: 989-993

33 Donders GG, Bellen G, Mendling W. Management of recurrent vulvovaginal candidosis as a chronic illness. Gynecol Obstet Invest 2010; 70: 306-321

34 Eckert LO, Hawes SE, Stevens CE et al. Vulvovaginal candidiasis: clinical manifestations, risk factors, management algorithm. Obstet Gynecol 1998; 92: 757-765

35 Ehrström SM, Kornfeld D, Thuresson J et al. Signs of chronic stress in women with recurrent candida vulvovaginitis. Am J Obstet Gynecol 2005; 193: 1376-1381

36 Falagas ME, Betsi GI, Athanasiou S. Probiotics for prevention of recurrent vulvovaginal candidiasis: a review. A Antimicrob Chemother 2006; 58: 266-272

37 Farmer MA, Taylor AM, Bailey AL et al. Repeated vulvovaginal fungal infections cause persistent pain in a mouse model of vulvodynia. Sci Transl Med 2011; 3: 101ra91

38 Farrell SM, Hawkins DF, Ryder TT. Scanning electron microscope study of Candida albicans, invasion of cultural human cervical epithelial cells. Sabouraudia 1983; 25: 251-254
39 Ferris GD, Nyirjesy P, Sobel JD et al. Over-the-counter antifungal drug misuse associated with patient-diagnosed vulvovaginal candidiasis. Obstet Gynecol 2002; 99: 419-425

40 Ferwerda B, Ferwerda B, Platinga TS et al. Human lectin-1 deficiency and mucocutaneous fungal infections. N Engl J Med 2009; 361: 17601767

41 Fidel PL jr. Immunity in vaginal candidiasis. Curr Opin Infect Dis 2005; 18: $107-111$

42 Fidel PL jr., Vazquez JA, Sobel JD. Candida glabrata: review of epidemiology, pathogenesis, and clinical disease with comparison to C. albicans. Clin Microbiol Rev 1999; 12: 80-96

43 Fong JW. The value of chronic suppressive therapy with itraconazole versus clotrimazole in women with recurrent vaginal candidiasis. Genitourin Med 1992; 68: 374-377

44 Foxman $B$. The epidemiology of vulvovaginal candidiasis: risk factors. Am J Public Health 1990; 80: 329-331

45 Foxman B, Muraglia R, Dietz JP et al. Prevalence of recurrent vulvovaginal candidiasis in 5 European countries and the United States: results from an internet panel survey. Low Genit Tract Dis 2012; 17: 1-6

46 Friese K, Neumann G, Siebert J. Topical antiseptics as an alternative in the treatment of acute vulvovaginal candidosis. Arch Gynecol Obstet 2003; 268: 194-197

47 Frey Tirri B. Antimicrobial topical agents used in the vagina. Curr Probl Dermatol 2011; 40: 36-47

48 Gaspard U, Scheen A et al. Randomized study over 13 cycles to assess the influence of oral contraceptives containing ethinylestradiol combined with drospirenone or desogestrel on carbohydrate metabilism. Contraception 2003; 67: 423-429

49 Geraldo P, Neuer A, Korneeva IL et al. Vaginal heat shock protein expression in symptom-free women with history of recurrent vulvovaginitis Am J Obstet Gynecol 1999; 180: 524-529

50 Ghannoum MA, Abu-El Teen. Pathogenecity determinants of Candida mycoses. 1990; 33: 265-282

51 Ghannoum MA. Potential role of phospholipases in virulence and fungal pathogenesis. Clin Microbiol Rev 2000; 13: 122-143

52 Goswami R, Dadhwal V, Tejaswi $S$ et al. Species-specific prevalence of vaginal candidiasis amoung patients with diabetes mellitus and its relation to their glycaemic status. J Infect Dis 2000; 41: 162-166

53 Goswami D, Goswami R, Banerjee U et al. Pattern of Candida species isolated from patients with diabetes mellitus and vulvovaginal candidiasis and their response to single dose oral fluconazole therapy. J Infect 2006; 52: 111-117

54 Hay PH, Czeizel AE. Asymptomatic trichomonas and candida colonization and pregnancy outcome. Best Pract Res Clin Obstet Gynecol 2007; 21: 403-409

55 Hettiarachchi N, Ashbee HR, Wilson JD. Prevalence and management of non-albicans vaginal candidiasis. Sex Transm Infect 2010; 86: 99-100

56 Hilton E, Isenberg HD, Alperstein P et al. Ingestion of yogurt containing Lactobacillus acidophilus as prophylaxis for candidal vaginitis. Ann Intern Med 1992: 116: 353-357

57 Hoffstetter SE, Barr S, LeFevre C et al. Self-reported yeast symptoms compared with clinical wet mount analysis and vaginal yeast culture in a specialty clinic setting. J Reprod Med 2008; 53: 402-406

58 Holland S, Vinh D. Yeast infections - human genetics in the rise. N Engl J Med 2009; 361: 1798-1801

59 Ip WK, Lan YL. Role of mannose-binding lectin in the innate defense against Candida albicans: enhancement of complement activation, but lack of opsonic function, in phagocytosis by human dendritic cells. J Inf Dis 2004; 190: 632-640

60 Ismail A, Lupan DM. Utilisation of siderophores by Candida albicans. Mycopath 1986; 96: 109-113

61 Jeavons HS. Prevention and treatment of vulvovaginal candidosis using exogenous lactobacilli. J Obstet Gynecol Neonatal Nurs 2003; 32: 287296

62 De Jong MA, Vriend LE, Theelen B et al. C-type lectin Langerhans is a beta-glucan receptor on human Langerhans cells that recognize opportunistic and pathogenic fungi. Mol Immunol 2010; 47: 1216-1225

63 Kiss H, Petricevicz L, Husslein P. Prospective randomised controlled trial of an infection screening program to reduce the rate of preterm delivery. BMJ 2004; 329: 371-375

64 Koldowsky H, Kariger $U$, Mendling $W$. Herstellung eines autologen membrangebundenen Candida-Antigens und in-vitro-Untersuchungen zu seinen immunologischen Reaktionen. In: Metzner G, Weissenbacher ER, Hrsg. Candida-Infektionen des weiblichen Genitaltraktes. München: Medifact; 1999: 25-32 
65 Kunzelmann V, Tietz HJ, Roßner D et al. Voraussetzungen für eine effektive Therapie chronisch rezidivierender Vaginalkandidosen. Mycoses 1996; 39 (Suppl. 1): 65-72

66 Lattif AA, Prasard $R$ et al. The glyzolate cycle enzyme activities in the pathogenitic isolates of Candida albicans obtained from HIV/AIDS, diabetic and burn patients. Mycoses 2006; 49: 85-89

67 de Leon E, Jacober SJ, Sobel JD et al. Prevalence and risk factors for vaginal Candida colonization in women with type I and type 2 diabetes. BMC Infect Dis 2002; 2: 1-6

68 Li J, Fan SR, Liu XP et al. Biased genotype distributions of Candida albicans strains associated with vulvovaginal candidosis and candidal balanoposthitis in China. Clin Infect Dis 2008; 47: 1119-1125

69 Loeffler W. Terminologie der Humanmykosen. Mykosen 1983; 26: 346

70 Lowe NK, Neal JL, Ryan-Wenger NA. Accuracy of the clinical diagnosis of vaginitis compared with a DNA probe labaratory standard. Obstet Gynecol 2009; 113: 89-95

71 Mailänder-Sánchez D, Wagener J et al. Potential role of probiotic bacteria in the treatment and prevention of localised candidosis. Mycoses 2012; 55: 17-26

72 Martinez RC, Seney SL, Summers KL et al. Effect of Lactobacillus rhamsosus GR-1 and Lactobacillus reuteri RC-14 on the ability of Candida albicans to infect cells and incluce inflammation. Microbiol Immunol 2009; 53: 487-495

73 Mastroiacovo P, Mazzone T, Botto LD. Prospective assessment of pregnancy outcome after first-trimester exposure to fluconazole. Am J Obstet Gynecol 1996; 176: 1645-1650

74 Mathema B, Cross E, Dun E et al. Prevalence of vaginal colonization by drug-resistent candida species in college-age women with previous exposure to over-the-counter azole antifungals. Clin Inf Dis 2001; 33: E23-E27

75 Meinhof W. Die Salzsäure-Toleranz von Candida albicans. Mykosen 1974; 17: 339-347

76 Mendling W. Die Torulopsidose in der Frauenheilkunde. Geburtsh Frauenheilk 1984; 44: 583-586

77 Mendling W. Azoles in the Therapy of vaginal Candidosis. In: Berg D, Plempel M, eds. Sterol Biosynthesis Inhibitors. Chichester: Ellis Horwood; 1988: 480-506

78 Mendling $W$, Koldovsky $U$. Investigations by cell-mediated immunologic tests of therapeutic trials with thymopentin in vaginal mycoses. Inf Dis Obstet Gynecol 1996; 4: 225-231

79 Mendling W, Gutschmidt J, Gantenberg R et al. Vergleich der Stammspezifität von Hefepilzen verschiedener Lokalisationen bei Frauen mit Vaginalcandidosen und deren Partnern. Mycoses 1998; 41 (Suppl. 2): 2225

80 Mendling W, Krauss C, Fladung B. A clinical multi-center-study comparing afficacy and tolerability of topical combination therapy with Clotrimazole (Canesten, two formats) with oral single dose fluconazole (Diflucan) in vulvovaginal mycoses. Mycoses 2004; 47: 136-142

81 Mendling W, Niemann D, Tintelnot $K$. Vaginal colonisation with Candida species with special focus on Candida dubliniensis. A prospective study. Geburtsh Frauenheilk 2007; 67: 1132-1137

82 Mendling W, Seebacher C. Vulvovaginalkandidose. AWMF-Guideline 013/004 (S1). 2008

83 Mendling $W$. Vaginose, Vaginitis, Zervizitis und Salpingitis. 2. Aufl. Heidelberg; Springer: 2006

84 Mendling W, Spitzbart H. Antimykotische Therapie der vaginalen Hefepilz-Kolonisation von Schwangeren zur Verhütung von Kandidamykosen beim Neugeborenen. AMWF, Guideline 015/042 (S1). 2008

85 Mendling W, Birkner V. Die Vakzination mit inaktivierten Laktobazillen oder Heliotherapie kann die Lebensqualität von Frauen mit chronisch rezidivierender vulvovaginaler Kandidose verbessern. - Eine prospektive, 3-armige randomisierte Studie. Geburtsh Frauenheilk 2011; 71: 767-772

86 Mendling $W$, Schlegelmilch $R$. Three-day combination treatment for vulvovaginal Candidosis with $200 \mathrm{mg}$ clotrimazol vaginal suppositories and clotrimazol cream for the vulva is significantly better than treatment with vaginal suppositories alone - an earlier, multi-centre, placebo-controlled double blind study. Geburtsh Frauenheilk 2014; 74: $355-360$

87 Meyer H, Göttlicher S, Mendling W. Stress as a cause of chronic recurrent vulvovaginal candidosis and the effectiveness of the conventional antimycotic therapy. Mycoses 2006; 48: 202-209

88 Molgaard-Nielsen D, Pasternak B, Hviid A. Use of fluconazole during pregnancy and risk of birth defects. N Engl J Med 2013; 369: 830-839
89 Moraes PSA, de Lima Goiaba S, Taketoni EA. Candida albicans allergen immunotherapy in recurrent vaginal candidiasis. Invest Allergol Clin Immunol 2000; 10: 305-309

90 Müller J, Nold B, Kubitza D et al. Quantitative Untersuchungen über die Döderlein-Flora gesunder sowie mykosekranker Probandinnen unter lokaler Isoconazol-Nitrat-Therapie. In: Seeliger HPR, Hrsg. Gyno Travogen, Monographie Excerpta Medica. Amsterdam: Oxford Princeton; 1981: 81-93

91 Mylonas I, Bergauer F. Diagnosis of vaginal discharge by wet mount microscopy: a simple and underrated method. Obstet Gynecol Surv 2011; 66: 359-368

92 Naglik J, Albrecht A, Bader $O$ et al. Candida albicans proteinases and host/pathogen interactions. Cellular Microbiology 2004; 6: 915-926

93 Neves NA, Carvallho LP, de Oliveira MA et al. Association between atopy and recurrent vaginal candidosis. Clin Exp Immunol 2005; 142: 167-171

94 Niewerth M, Kunze D, Seibold $M$ et al. Ciclopirox olamine treatment affects the expression pattern of metabolism proteins, and drug resistance factors. Antimicrob Agents Chemother 2003; 47: 1805-1817

95 Nurbhai M, Grimshaw J, Watson M et al. Oral versus intra-vaginal imidazole and triazole anti-fungal treatment of uncomplicated vulvovaginal candidiasis (thrush). Cochrane Database Syst Rev 2007; 4: CD002845

96 Nyirjesy P, Seeney SM, Grody MH et al. Chronic fungal vaginitis: the value of cultures. Am J Obstet Gynecol 1995; 173: 820-823

97 Nyirjesy P, Alexander $A B$, Weitz MV. Vaginal candida parapsilosis: pathogen or bystander? Infect Dis Obstet Gynecol 2005; 13: 37-41

98 Odds FC. Candida and Candidosis. 2nd ed. Bailliére Tindall: WB Saunders; 1988

99 Odds FC, Arai T, Disalvo AF et al. Nomenclature of fungal diseases: a report and recommendations from a sub-Committee of the International Society for Human and Animal Mycology (ISHAM). J Med Vet Mycol 1992; 30: 1-10

100 Paulitsch A, Weger W, Ginter-Hanselmayer G et al. A 5-year (20002004) epidemiological survey of Candida and non-candida yeasts species causing vulvovaginal candidiasis in Graz, Austria. Mycoses 2006; 49: 471-475

101 Phillips AJ. Treatment of non-albicans candida vaginitis with amphotericin B vaginal suppositories. Am J Obstet Gynecol 2005; 192: 20092012

102 Pirotta MV, Gunn JM, Chondros P. “Not thrush again!” Women's experience of post-antibiotic vulvovaginitis. Med J Aust 2003; 179: 43-46

103 Pirotta M, Gunn J, Chondros P et al. Effect of lactobacillus in preventing post-antibiotic vulvovaginal candidiasis: a randomised controlled trial. BMJ 2004; 329: 548-551

104 Pirotta MV, Garland SM. Genital Candida species detected in samples from women in Melbourne, Australia, before and after treatment with antibiotics. J Clin Microbiol 2006; 44: 3213-3217

105 Pitsoni E, Lavazzo C, Falagas ME. Itraconazole vs. fluconazole for the treatment of uncomplicated acute vaginal and vulvovaginal candidiasis in nonpregnant women: a metaanalysis of randomised controlled trials. Am J Obstet Gynecol 2008; 198: 153-160

106 Plempel M. Pharmakokinetik der Imidazol-Antimykotika. Mykosen 1980; 23: 16-27

107 Powell BL. Identification of a 173-estradiol-bindig protein in Candida albicans and Candida (Torulopsis) glabrata. Exp Mycology 1984; 8: 304

108 Quereux C, Gelas B, Chevallier T et al. Evaluation of the efficacy and speed of action of sertoconazole nitrate suppository and cream combined treatment for vulvovaginal candidiasis. Gynecol Obstet Fertil 2000; 28: 238-244

109 Ray D, Goswami R, Bomerjee $U$ et al. Prevalence of Candida glabrata and its response to boric acid vaginal suppositories in comparison with oral fluconazole in patients with diabetes and vulvovaginal candidiasis. Diabetes Care 2007; 30: 312-317

110 Raska M, Belakova J, Horynova $M$ et al. Systemic and mucosal immunization with Candida albicans hsp90 elicits hsp90-specific humoral response in vaginal mucosa which is further enhanced during experimental vaginal candidiasis. Med Mycol 2008; 46: 411-420

111 Reed BD, Zazone P, Pierson LL et al. Candida transmission and sexual behaviour as risk for a repeated episode of Candida vulvovaginitis. J Womens Health (Larchmt) 2003; 12: 979-989

112 Richter SS, Galask RP, Messer SA et al. Antifungal susceptibilities of Candida species causing vulvovaginitis and epidemiology of recurrent cases. J Clin Microbiol 2005; 43: 2155-2162 
113 Rigg D, Miller MM, Metzger WJ. Recurrent allergic vulvo-vaginitis treatment with Candida albicans allergen immunotherapy. Am J Obstet Gynecol 1990; 162: 332-336

114 Ritter W. Pharmacokinetics of Azole Compounds. In: Berg D, Plempel M, eds. Sterol Biosynthesis Inhibitors. Chichester: Ellis Horwood; 1988: 397-429

115 Roberts CL, Rickard K, Kotsiou G et al. Treatment of asymptomatic vaginal candidiasis in pregnancy to prevent preterm birth: an open-label pilot randomized controlled trial. BMC Pregnancy Childbirth 2011; 11: 18

116 Romani L. Immunity to fungal infections. Nat Rev Immunol 2011; 11 : 275-288

117 Romeo O, Criseo G. Candida africana and its closest relatives. Mycoses 2011; 54: 475-486

118 Rosedale N, Browne K. Hyposensitisation in the management of recurring vaginal candidiasis. Ann Allergy 1979; 43: 250-253

119 Roth AC, Milsom I, Forssman L et al. Intermittent prophylactic treatment of recurrent vaginal candidiasis by postmenstrual application of a $500 \mathrm{mg}$ clotrimazole vaginal tablet. Genitourin Med 1990; 66: 357-360

120 Rüchel R, Fegeler R, Trost M. Comparison of secretory proteinases from different strains of Candida albicans. Sabouraudia 1982; 20: 233-244

121 Rusch K, Schwiertz A. Candida autovaccination in the treatment of vulvovaginal Candida infections. Int J Gynecol Obstet 2007; 96: 130

122 Rylander E, Berglund A-L, Krassny C et al. Vulvovaginal candida in a young sexually active population: prevalence and association with oro-genital sex and frequent pain at intercourse. Sex Transm Infect 2004; 80: 54-57

123 Savini V, Catavitello C, Manua A et al. Two cases of vaginitis caused by Itraconazole - resistant Saccharomyces cerevisiae and review of recently published studies. Mycopathologia 2008; 166: 47-50

124 Scheklakow ND, Deletorski WW, Goldoa OA. Veränderungen der Ultrastruktur von Candida albicans unter Einwirkung von Polyen-Antibiotika. Mykosen 1980; 24: 140-152

125 Schnell JD. Epidemiology and prevention of peripartal mycoses. Chemother 1982; 28 (Suppl. I): 66-72

126 Schnell JD, Voigt WH. Das Verhalten von Sprosspilzen am nicht verhornenden Plattenepithel. Arch Gynaekol 1974; 217: 377-382

127 Shahid Z, Sobel JD. Reduced fluconazole susceptibility of Candida albicans isolates in women with recurrent vulvovaginal candidiasis: effects of long-term fluconazole therapy. Diagn Microbiol Infect Dis 2009; 64: 354-356

128 Sharma C, Muralidhar S, Xu J et al. Multilocus sequence typing of Candida africana from patients with vulvovaginal candidiasis in New Delhi, India. Mycoses 2014; 57: 544-552

129 Singh S, Sobel JD, Bhargava P et al. Vaginitis due to candida krusei: epidemiology, clinical aspects, and therapy. Clin Inf Dis 2002; 35: 10661070

130 Sobel JD. Management of recurrent vulvovaginal candidiasis with intermittent ketoconazole prophylaxis. Obstet Gynecol 1985; 65: 435440

131 Sobel JD. Vaginitis due to Saccharomyces cereviseae: epidemiology, clinical aspects, and therapy. Clin Inf Dis 1993; 16: 93-99

132 Sobel JD. Vulvovaginitis due to Candida glabrata. An emerging problem. Mycoses 1998; 41 (Suppl. 2): 18-21

133 Sobel JD. Vulvovaginal candidosis. Lancet 2007; 369: 1961-1971

134 Sobel JD, Harold C, Wiesenfeld MD et al. Maintenance fluconazole therapy for recurrent vulvovaginal Candidiasis. N Engl J Med 2004; 351: 876-883

135 Sobel JD, Myers PG, Kaye D et al. Adherence of Candida albicans to human vaginal and buccal epithelial cells. J Infect Dis 1981; 143: 76-82

136 Sobel JD, Zervos M, Reed BD et al. Fluconazole susceptibility of vaginal isolates obtained from women with complicated Candida vaginitis: clinical implications. Antimicrob Agents Chemother 2003; 47: 34-38

137 Spacek J, Jilek P, Buchtav et al. The serum levels of calcium, magnesium, iron and zinc in patients with recurrent vulvovaginal candidosis during attack, remission and in healthy controls. Mycoses 2005; 48: 391-395
138 Spinillo A, Capuzzo E, Egbe TO et al. Torulopsis glabrata vaginitis. Obstet Gynecol 1995; 85: 993-998

139 Swidsinski A, Loening-Baucke $V$, Mendling $W$ et al. Infection through structured polymicrobial Gardnerella biofilms (StPM-GB). Histol Histopathol 2014; 29: 567-587

140 Tarry W, Fisher M, Shen S et al. Candida albicans: the estrogen target for vaginal colonization. J Surg Res 2005; 129: 278-282

141 Thoden J, Potthoff A, Bogner JR et al. Therapy and prophylaxis of the opportunistic infections in HIV-infected patients: a guideline by the German and Austrian AIDS societies (DAIG/ÖAG) (AWMF 055/066). Infection 2013; 41 (Suppl. 2): S91-S115

142 Thrumbore DJ, Sobel JD. Recurrent vulvovaginal candidiasis: vaginal epithelial cells susceptibility to Candida albicans adherence. Obstet Gynecol 1986; 67: 810-812

143 Tietz HJ. Gezieltes Vorgehen gegen Problemkeime. Gyn Geburtsh 2009; 7-8: 41-44

144 Tietz HJ. Candida glabrata: Pathogenität und Stand der Dinge. Hautarzt 2012; 63: 868-871

145 Upmalis DH, Cone FL, Lamia CA et al. Single-dose miconazole nitrate vaginal ovule in the treatment of vulvovaginal candidiasis: two single-blind, controlled studies versus miconazole nitrate $100 \mathrm{mg}$ cream for 7 days. J. Womens Health Gend Based Med 2000; 9: 421-429

146 Vecciarelli A, Pericolini E, Pietrella D. New approaches in the development of a vaccine for mucosal Candidiasis: progress and challenges. Front Microbiol 2012; 3: 294

147 Vermitsky JP, Self MJ, Chadwick SG et al. Survey of vaginal flora-flora Candida species isolates from women of different age groups by use of species-specific PCR detection. J Clin Microbiol 2008; 46: 15011503

148 Wajnberg M, Wajnberg A. Doppelblind-Vergleichsstudie mit Ciclopyroxolamin- und Miconazol-Vaginalcreme bei vulvovaginaler Kandidose. Mykosen 1981; 24: 721-730

149 Walker PP, Reynolds MT, Ashbee HR et al. Vaginal yeasts in the era of "over the counter" antifungals. Sex Transm Infect 2000; 76: 437-238

150 Watson MC, Grimshaw JM, Bond CM et al. Oval versus intravaginal imidazole and triazole antifungal treatment of uncomplicated Candidiasis (thrush): a systemic review. BJOG 2002; 109: 85-89

151 Weissenbacher TM, Witkin SS, Gingelmaier A et al. Relationship between recurrent vulvovaginal candidosis and immune mediators in vaginal fluid. Eur J Obstet Gynecol Reprod Biol 2009; 144: 59-63

152 Weissenbacher T, Witkin SS, Ledger WJ et al. Relationship between clinical diagnosis of recurrent vulvovaginal candidiasis and detection of Candida species by culture and polymerase chain reaction. Arch Gynecol Obstet 2009; 279: 125-129

153 van de Wijgert JH, Verwijs MC, Turner AN et al. Hormonal contraception decreases bacterial vaginosis but oral contraception may increase candidiasis: implications for HIV transmission. AIDS 2013; 27: 2141-2153

154 Wilson C. Recurrent vulvovaginal candidiasis; an overview of traditional and alternative therapies. Adv Nurse Pract 2005; 13: 24-29

155 Witkin SS, Jeremias J, Ledger WJ. A localized vaginal allergic response in women with recurrent vaginitis. J Allergy Clin Immunol 1988; 81: $412-416$

156 Witkin SS, Giraldo P, Linhares D. New insights into the immune pathogenesis of recurrent vulvovaginal candidiasis. Int J Gynecol Obstet 2000; 3: 114-118

157 Witt A, Kaufmann U, Bitschnau $M$ et al. Monthly itraconazole versus classic homeopathy for the treatment of recurrent vulvovaginal candidiasis: a randomised trial. BJOG 2009; 11: 1499-1505

158 Wozniak KL, Palmer G, Kutner R et al. Immunotherapeutic approaches to enhance protective immunity against Candida vaginitis. Med Mycol 2005; 43: 589-601

$159 \mathrm{Xu}$ J, Schwartz K, Bartoces $M$ et al. Effect of antibiotics on vulvovaginal candidiasis: a MetroNet study. J Am Board Fam Med 2008; 21: 261208

160 Young GL, Jewell D. Topical treatment for vaginal candidiasis (thrush) in pregnancy. Cochrane Database Syst Rev 2001; 4: CD000225

161 von Zglinicki W. Die Hormonspirale als Ursache für chronische Infektionen. Dissertation (Prof. HJ Tietz). Charité; 2011 


\section{Annex Guideline Report}

\section{Consensus procedure}

The guideline was developed in participation with a representative group of professional users. Because it represents an update with relatively limited changes, a consensus meeting was not held. The changes were gathered using a written DELPHI-procedure, summarized by the coordinator and then inserted. In a total of three rounds, this final version was unanimously adopted.

\section{Patient participation}

Patient representatives were not involved due to the lack of appropriate patient organizations.

\section{Assessment and management of potential conflicts of interest}

All contributors filled out the Association of the Scientific Medical Societies (AWMF) form. The majority of contributors reported financial relationships with companies. Conflicts of interest were not specifically examined. Formal, consensus-based working methods were used to prevent the distorted communication of results by the guideline working group.

\section{$4 \quad$ Participation of professional societies/approval} This guideline was approved by the following professional societies and contributors:

- German Society for Gynecology and Obstetrics (DGGG - Deutsche Gesellschaft für Gynäkologie und Geburtshilfe)

- Working Group on Infections and Immuology in Gynecology and Obstetrics (AGII - Arbeitsgemeinschaft für Infektionen und Infektionsimmunologie in der Gynäkologie und Geburtshilfe)
- German Dermatological Society (DDG - Deutsche Dermatologische Gesellschaft)

- German Mycological Society (DmykG - Deutschsprachige Mykologische Gesellschaft)

\section{$5 \quad$ Validity/Updates}

The validity of these guidelines was confirmed by the Executive Board of the DGGG and the DGGG Guidelines Commission in December 2013.

This guideline is valid until 12/2016.

If potentially relevant changes should occur in the meantime, these will be communicated to the working group by the coordinator and it will be decided whether a revision or addendum is necessary. Comments on the guideline are welcome.

Guideline Coordinator: Prof. W. Mendling.

The "guidelines" of the Scientific Medical Professional Societies (Wissenschaftliche Medizinische Fachgesellschaften) are systematically developed aids for the physician in decision-making for specific situations. They are based on current scientific knowledge and practically established procedures and thus serve to provide more safety in medicine while also taking economic aspects into consideration. The "guidelines" are not legally binding for physicians and thus provide neither a basis for liability claims nor for a freedom from liability. The AWMF compiles and publishes the guidelines of the professional societies with the greatest possible care - even so the AWMF cannot accept any responsibility for the correctness of the contents. Especially in the case of dosages, the details provided by the respective manufacturer should always be consulted!

\begin{tabular}{|ll}
\hline Homepage & http://www.awmf.org/leitlinien/detail/ll/015-072.html \\
\hline Date of completion & 31.12 .2013 \\
\hline Next assessment scheduled & 31.12 .2016 \\
\hline Declaration of conflicts of interests & See the AWMF web site: http://www.awmf.org/leitlinien/detai//l/015-072.html \\
\hline Participating medical professional & German Society for Gynecology and Obstetrics (Deutsche Gesellschaft für Gynäkologie und Geburtshilfe \\
societies and organisations & DGGG) e.V. (responsible) \\
& Working Group on Infections and Immunology in Gynecology and Obstetrics \\
& (Arbeitsgemeinschaft für Infektionen und Infektionsimmunologie in der Gynäkologie und Geburtshilfe AGII) \\
& - German Dermatological Society (Deutsche Dermatologische Gesellschaft DDG) \\
& German Mycological Society (Deutschsprachige Mykologische Gesellschaft DMyKG)
\end{tabular}

